\title{
Development of High-Power Hall Thruster Power Processing Units at NASA GRC
}

\author{
Luis R. Piñero ${ }^{1}$, Karin E. Bozak ${ }^{2}$, Walter Santiago ${ }^{3}$ and Robert J. Scheidegger ${ }^{3}$, \\ NASA Glenn Research Center, Cleveland, OH 44135 \\ and \\ Arthur G. Birchenough ${ }^{4}$ \\ Vantage Partners, LLC, Brook Park, OH 44142
}

\begin{abstract}
NASA GRC successfully designed, built and tested four different power processor concepts for high power Hall thrusters. Each design satisfies unique goals including the evaluation of a novel silicon carbide semiconductor technology, validation of innovative circuits to overcome the problems with high input voltage converter design, development of a direct-drive unit to demonstrate potential benefits, or simply identification of lessonslearned from the development of a PPU using a conventional design approach. Any of these designs could be developed further to satisfy NASA's needs for high power electric propulsion in the near future.
\end{abstract}

\section{Introduction}

$\mathrm{H}$ igh-power electric propulsion is an enabling technology for a variety of missions from LEO-to-GEO transfer space tugs to Mars missions. Hall thrusters with a high thrust to power ratio are a good candidate to meet NASA's near-term mission needs and are also extensible to much higher power levels in support of future Human exploration needs. ${ }^{1-5}$ NASA's Space Technology Mission Directorate (STMD) is sponsoring Glenn Research Center (GRC) to develop a high-power Hall thruster and power processing unit (PPU) technologies applicable to these missions. To further advance the maturity of solar electric propulsion (SEP), a technology demonstration mission (TDM) is being formulated. Several mission concepts have been developed including the Asteroid Redirect Robotic Mission (ARRM), which uses SEP to return several tons asteroidal mass from the surface of a larger asteroid, to a stable orbit around the Moon for subsequent access by a human crewed mission. SEP/TDM will demonstrate not only high-power SEP but also many other technologies like high-power solar arrays that are also critical for future exploration goals.

Since 2011, GRC has led the development of high power PPUs for STMD. Changes in requirements and design goals resulted in four distinct PPU developments. Each PPU development leveraged as much as possible from the previous efforts and followed the same design approach. The four units developed include a PPU with a high input voltage of $300 \mathrm{~V}$, a $300 \mathrm{~V}$ direct-drive unit (DDU), a PPU with a $120 \mathrm{~V}$ input, and a discharge module with a wide high input voltage range of 300 to $600 \mathrm{~V}$. All these designs are described in more detail in this paper.

\section{System Overview}

The PPUs under development were designed to operate a high-power Hall thruster being developed by a team comprised of GRC and JPL personnel. The thruster, designated Hall Effect Rocket with Magnetic Shielding (HERMeS), can operate up to $12.5 \mathrm{~kW}$ and a peak efficiency of 64 percent. It can achieve a specific impulse of $3,000 \mathrm{~s}$ at a discharge voltage of $800 \mathrm{~V}$. HERMeS uses magnetic shielding to mitigate erosion of the discharge chamber walls and extend thruster life. ${ }^{6}$

\footnotetext{
${ }^{1}$ Senior Electrical Engineer, Electric Propulsion Systems Branch, 21000 Brookpark Rd, Associate Fellow.

${ }^{2}$ Electrical Engineer, Power Management and Distribution Branch, 21000 Brookpark Rd.

${ }^{3}$ Senior Electrical Engineer, Power Management and Distribution Branch, 21000 Brookpark Rd.

${ }^{4}$ Senior Electrical Engineer, Power Management and Distribution Branch, 3000 Aerospace Pkwy.
} 


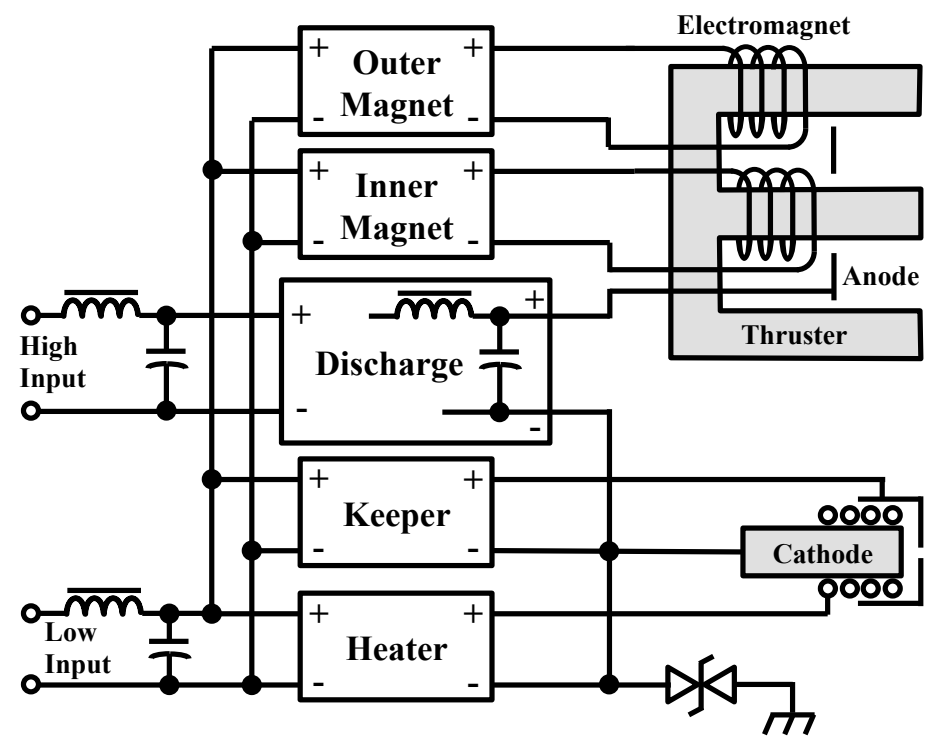

Figure 1. Simplified block diagram of a Hall PPU

Figure 1 shows the input and output power interfaces for the PPU configuration used for this development effort. The discharge supply is the most important part of the PPU since it provides power to ionize the propellant and provides the high voltage that accelerates the ions to produce thrust. The other power supplies, also referred to as the auxiliary supplies, provide several other thruster functions. The magnet supplies power the inner and outer electromagnets to stabilize the main discharge. Individual power supplies were used for the inner and outer magnet supply for maximum control of thruster operation. The keeper and heater supplies are used to heat and ignite the cathode prior to operation with a main discharge. Another important aspect of the PPU design is the output filter of the discharge supply. It is necessary that it has enough capacitance to sustain the typical current oscillations caused by the main discharge. Single and double L-C low-pass filters have been previously implemented for this filter depending on the magnitude of the oscillations and the attenuation desired. ${ }^{7-8}$

On the input side of the PPU, two separate inputs were used to supply power for the converters. A high input voltage was used to power the discharge supply to minimize conduction losses since it processes up to $99 \%$ of the power in the system. A low input voltage was used to power the auxiliary supplies and housekeeping functions.

\section{PPU Design}

PPU work started with preliminary input and output requirements. As potential TDM missions evolved, so did these requirements and the objectives of the PPU development effort including. These requirements included:

- identifying the challenges and difficulties behind the development of high power PPUs;

- experimenting and demonstrating the capability of new power electronics technologies that could enable the development of future high power electric propulsion systems;

- developing innovative circuits to overcome the challenges of high power PPU design; and

- developing high power PPUs baseline designs for future flight PPU developments.

The following design rules were used for PPU development:

- modularity to optimize circuit design, allow reconfiguration, facilitate scaling, and interchangeablility between various PPU designs;

- extensiblility to higher power levels;

- common converters, assemblies, printed wiring boards (PWB), circuits, and components;

- simple electrical and mechanical designs;

- maximize performance and minimize mass;

- use parts with flight equivalents;

- include as much functionality for flight as possible;

- apply as many flight processes as possible to a brassboard level unit; and

- leverage experience and lessons-learned from previous NASA PPU development projects like NEXT $^{9-11}$, HiVHAc $^{12}$ and NSTAR. ${ }^{13-14}$

The same overall PPU architecture was applied to all designs. The discharge supply was designed in modules so the outputs could be connected in series or parallel to obtain the desired output voltage or current. An auxiliary module contains the four auxiliary supplies. The filter module contains the required input and output filters and other ancillary circuits, such as telemetry, fault protection, controls, interlocks, clocks, and interface between the PPU and a digital controller for the propulsion system are consolidated into a master control board in the master module. 
The overall strategy for power converter electronic design was to use the full-bridge topology shown in Fig. 2. This topology is good for high power applications because it has low electrical stress on the power transistors and very good transformer utilization. MOSFETs were paralleled as needed on each leg of the bridge to reduce conduction losses on the transistors. The full bridge topology was also chosen for the auxiliary converters to allow for ample room for growth and to be able to reuse control and gate drive PWBs. Only a single MOSFET per leg was necessary for the auxiliary converter because the current implementation only required a few hundred watts.

Breadboard circuits of the power converters for the discharge and auxiliary supplies were built and tested. These were used to evaluate the main power transformer, output inductor, and gate drive circuit design. The design was then used to develop a brassboard PPU capable of operating in vacuum. The overall strategy for thermal design consisted of locating components with high heat dissipation, like transformers, inductors, MOSFETs, and diodes, such that they have a direct thermal path to the baseplate. Printed circuit boards have thermal planes and are mounted vertically to an aluminum bracket that removed heat from the perimeter of the PWB into the baseplate.

The first PPU design operates off a nominal input of $300 \mathrm{~V}$
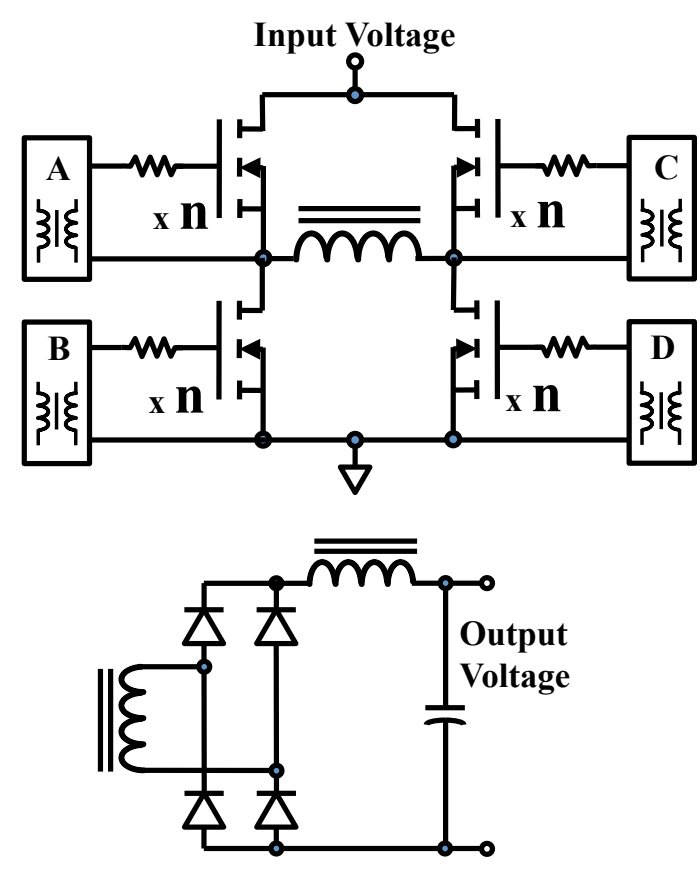

Figure 2. Full-bridge converter topology and outputs up to $15 \mathrm{~kW}$ at $400 \mathrm{~V}$. This unit uses commercial high-voltage silicon carbide (SiC) power semiconductors. From this design, a DDU compatible with a $300 \mathrm{~V}$ array was also developed. The third PPU operates off an input voltage range of 95 to $140 \mathrm{~V}$ and outputs up to $14 \mathrm{~kW}$ at $800 \mathrm{~V}$. This design is compatible with state-of-the-art (SOA) solar arrays, power systems, and spacecraft busses. Lastly, two discharge modules using an innovative topology known as the auto-balancing series-stacked (ABSS) were developed. The ABSS allows the use low voltage transistors to process power from a high voltage input. The sections below discuss each one of these designs, including specifications, design descriptions, and test results.

\section{A. Specifications}

\section{300V SiC PPU}

The first PPU was developed for a mission that would use a regulated high-voltage solar array and a Hall thruster with a specific impulse of 2,000 s. The discharge supply operates off an input voltage range of 270 to $330 \mathrm{~V}$ input and is capable of supplying up to $15 \mathrm{~kW}$ of power at discharge voltages from 300 to $500 \mathrm{~V}$. The $300 \mathrm{~V}$ input provides extensibility to high power by reducing conduction losses in the PPU. Another input of 23 to $36 \mathrm{~V}$ was used to power the auxiliary supplies and housekeeping functions. Table 1 summarizes the electrical input and output specifications used for this PPU.

One of the challenges of building a PPU with a high input voltage is the lack of space-qualified, radiationhardened transistors. Beyond $250 \mathrm{~V}$, there are very few transistors available and those that are available have low current and power ratings. At the time this development program started, the first practical, commercial-grade, silicon carbide MOSFETs became available. Devices with 1,200 V and 50 A ratings could be used to develop a 15 $\mathrm{kW}$ PPU. It was decided to use these parts to build the discharge supply and evaluate the potential of this new technology. 
Table 1. Electrical specifications for the 300V SiC PPU

\begin{tabular}{|c|c|c|c|c|}
\hline & Discharge & Magnets & Keeper & Heater \\
\hline $\begin{array}{l}\text { Output } \\
\text { Voltage }\end{array}$ & $300-500 \mathrm{~V}$ & $2-20 \mathrm{~V}$ & $10-30 \mathrm{~V}$ & $6-36 \mathrm{~V}$ \\
\hline $\begin{array}{l}\text { Output } \\
\text { Current }\end{array}$ & $10-50 \mathrm{~A}$ & $1-10 \mathrm{~A}$ & $1-3 A$ & $3-9 A$ \\
\hline $\begin{array}{l}\text { Maximum } \\
\text { Output } \\
\text { Power }\end{array}$ & $15 \mathrm{~kW}$ & $200 \mathrm{~W}$ & $90 \mathrm{~W}$ & $324 \mathrm{~W}$ \\
\hline $\begin{array}{l}\text { Regulation } \\
\text { Mode }\end{array}$ & $\begin{array}{l}\text { Voltage or } \\
\text { Current }\end{array}$ & & Current & \\
\hline $\begin{array}{l}\text { Line/Load } \\
\text { Regulation }\end{array}$ & \multicolumn{4}{|c|}{$\leq 2 \%$} \\
\hline Ripple & \multicolumn{4}{|c|}{$\leq 5 \%$} \\
\hline $\begin{array}{c}\text { Input } \\
\text { Voltage }\end{array}$ & $270-330 \mathrm{~V}$ & & $23-36 \mathrm{~V}$ & \\
\hline
\end{tabular}

\section{B. Design}

After a trade between mass and performance, it was decided that the discharge supply would consist of two 7.5 $\mathrm{kW}$ modules with their outputs connected in parallel, as shown in Fig. 3, to limit the output current from each module to approximately $25 \mathrm{~A}$. The full-bridge topology for this module uses three MOSFETs in parallel on each leg of the full-bridge to reduce conduction losses and meet the necessary current derating. A galvanically-isolated gate drive circuit that can provide $25 \mathrm{~V}$ and $-5 \mathrm{~V}$ to the SiC MOSFETs was developed. These gate drive requirements were developed from experimentation with a breadboard discharge module and were necessary to fully turn on and turn off the SiC MOSFETs to reduce switching and conduction losses. ${ }^{15}$ The main power transformer was built with a ferrite U-core using split windings and interleaving techniques to reduce leakage inductance. The input and output filter inductors were built on amorphous metal C-cores for its high saturation flux density. All magnetics were potted with thermally conductive epoxy and mounted on an aluminum heatsink so that they could be bolted to the PPU baseplate for maximum heat rejection. In addition to the two discharge modules, the PPU includes an auxiliary module and a filter/master module that contains the $300 \mathrm{~V}$ and $28 \mathrm{~V}$ input filters and the master control board.

\section{Testing}

A comprehensive bench top test was conducted to measure the functionality and performance of the $300 \mathrm{~V} \mathrm{SiC} \mathrm{brassboard} \mathrm{PPU.} \mathrm{During}$ this test, performance parameters such as input and output voltages, regulation, ripple, telemetry and setpoint accuracy were validated. All PPU inputs and outputs were instrumented with digital multi-meters and current shunts to measure DC performance. A digital oscilloscope with current probes was used to measure and characterize input and output ripples. Thermocouples were installed on components with high power dissipation to measure operating temperatures. A resistive load was used to simulate steady-state operation of the thruster discharge, magnets and keeper during these tests. Total PPU efficiency was calculated as the

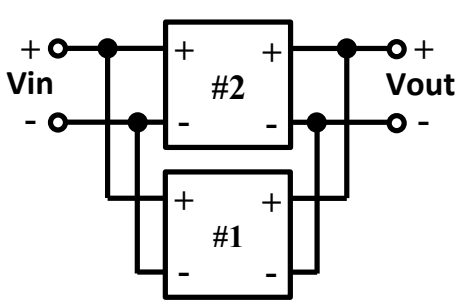

Figure 3. 300V SiC PPU discharge supply configuration ratio of all power outputs to all power inputs. 


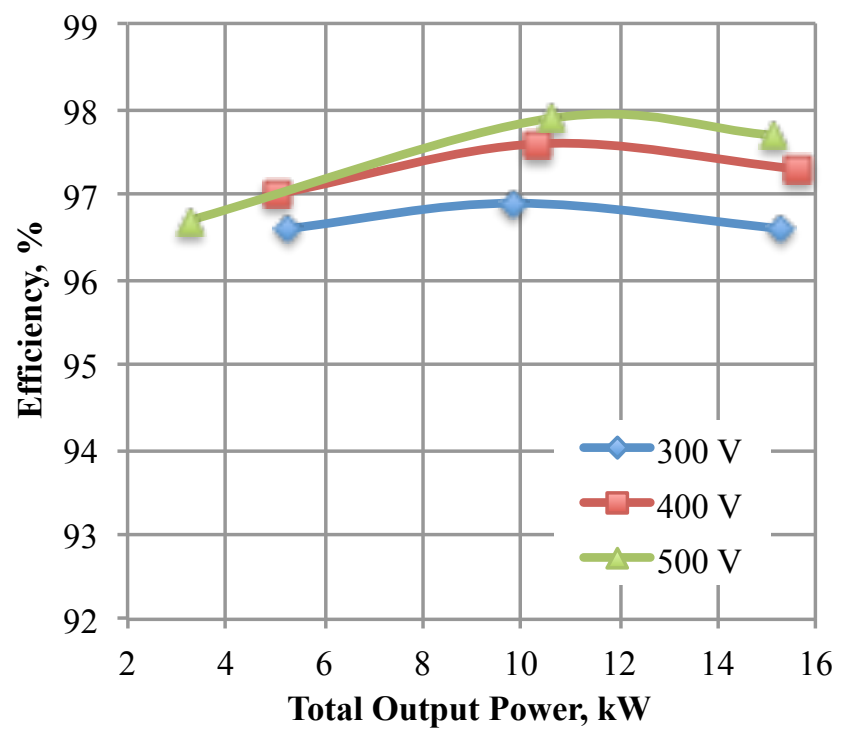

Figure 4. 300V SiC PPU efficiency vs. total output power for several discharge voltages

Figure 4 shows a plot of PPU total efficiency as a function of output power for several discharge voltages. With the magnet and keeper supplies operating at levels representative of the thruster, the PPU demonstrated total efficiencies of almost $98 \%$ at $12 \mathrm{~kW}$ and $500 \mathrm{~V}$ discharge voltage. The efficiency was better than $96.5 \%$ for the entire range.

Other performance parameters like ripple, regulation and telemetry were within specifications. Measurements revealed a temperature rise of about $30{ }^{\circ} \mathrm{C}$ in the main power transformer and output inductor for the discharge supply. However, the temperatures on those devices were still within derating guidelines. The temperature rise of other components was less than $20{ }^{\circ} \mathrm{C}$.

Functional and performance tests were repeated in a vacuum environment to validate the PPU thermal design. Vacuum Facility 8 at NASA GRC was used for this test. Figure 5 shows a photograph of the PPU installed in the facility. The PPU was mounted on a water-cooled aluminum plate to conductively reject heat through the baseplate. It could also be used to bake-out the PPU or increase operating temperature. The PPU was successfully operated at in vacuum at 25 and $50^{\circ} \mathrm{C}$ baseplate temperature with minimal impact in performance. A companion paper by Bozak provides additional information on the testing of the $300 \mathrm{~V} \mathrm{SiC} \mathrm{PPU.}{ }^{16}$

The 300V SiC PPU was successfully integrated with the HERMeS thruster. Stable operation of all power supplies was demonstrated at discharge voltages of 300 and $400 \mathrm{~V}$. Discharge current was characterized to assess performance of the discharge supply output filter. The discharge output filter was sufficient to control discharge oscillations and thruster performance the same as when operating with laboratory supplies.

\section{V.300V DDU}

\section{A. Design}

In a direct-drive system, power from the solar arrays is fed directly into the discharge of the Hall thruster. Only a discharge filter and an activation switch to energize and provide fault protection are needed, eliminating the need for a discharge supply. A simplified block diagram of such a system is shown in Fig. 6. This could result in significant mass savings and higher efficiency compared to a conventional PPU. A DDU for operation of a single thruster was derived from the $300 \mathrm{~V} \mathrm{SiC} \mathrm{PPU.} \mathrm{The} \mathrm{two} \mathrm{discharge}$ modules were replaced by a discharge filter module that contains the discharge filter components and telemetry circuits. An auxiliary module identical to that of the $300 \mathrm{~V}$ SiC PPU was included. The input filter module was used for the $28 \mathrm{~V}$ filter for the auxiliary module and for the activation relay. In future designs, this mechanical relay could be replaced with a hybrid switch that combines a relay and semiconductor devices to improve reliability and transient response. A photograph of the $300 \mathrm{~V}$ DDU is shown in Fig.

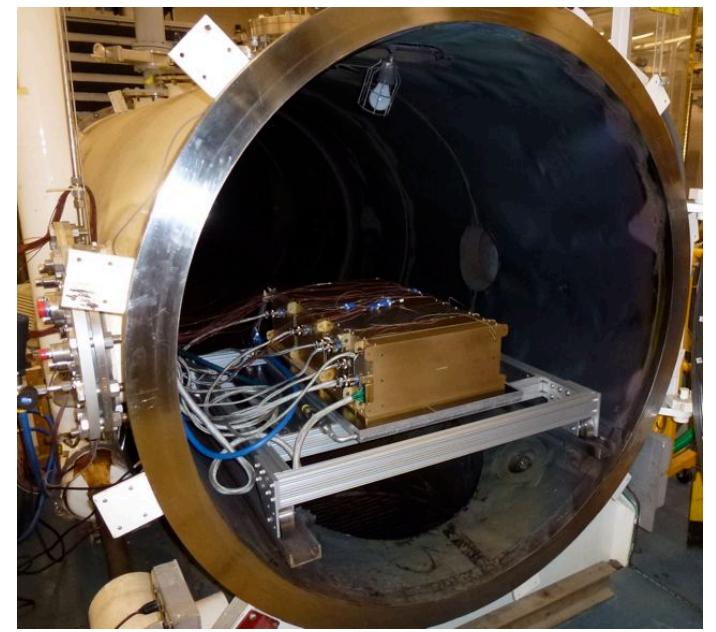

Figure 5. 300V SiC PPU in VF-8 for vacuum testing

7. The mass of the brassboard DDU without being optimized for performance and packaging is $24 \mathrm{~kg}$. This is about $50 \%$ lower than the mass of the $300 \mathrm{~V} \mathrm{SiC} \mathrm{PPU}$ and demonstrates one of the benefits of direct-drive. 


\section{B. Testing}

The primary test objective of the DDU was to measure performance and validate the activation and fault protection functions. The DDU was connected to a resistive load and a laboratory power supply to simulate the solar array. The auxiliary supplies were operated at conditions representative of the HERMeS thruster. At a full power operating condition of $15 \mathrm{~kW}$ and $300 \mathrm{~V}$, the DDU demonstrated an efficiency of $99.2 \%$ and better than $98 \%$ down to $5 \mathrm{~kW}$. This is an improvement of approximately $2 \%$ than the $300 \mathrm{~V} \mathrm{SiC} \mathrm{PPU.}$

Figure 8 shows waveforms of the input and discharge voltages and currents. After applying input voltage, the activation switch was turned on and discharge power was applied to the resistive load. Before time " $\mathrm{t0}$ ", the DDU is supplying approximately $300 \mathrm{~V}$ and 50 A to the load. At time "t0", a short-

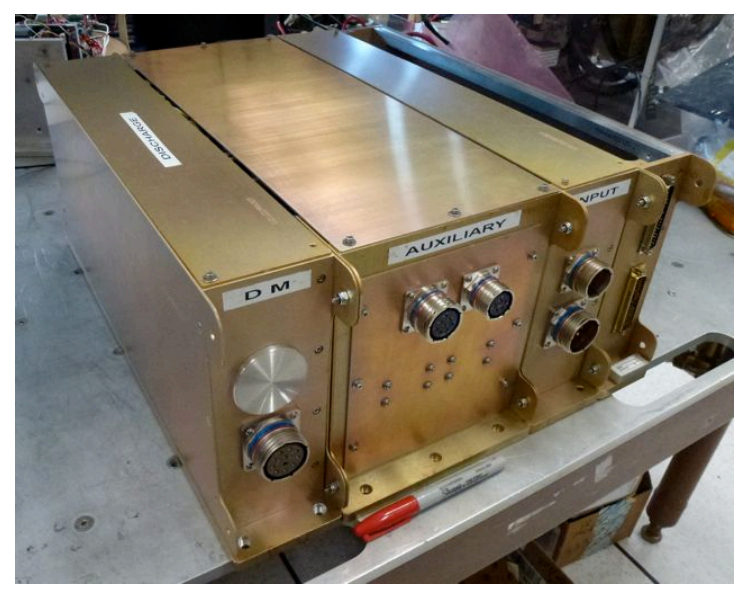

Figure 7. Photograph of brassboard DDU

developing control algorithms for the Hall propulsion system. ${ }^{17-19}$ Solutions to these problems and the successful development of high voltage solar arrays are needed before applying this technology.

\section{120V PPU}

\section{A. Specifications}

A third PPU was developed for a mission with a nominal $120 \mathrm{~V}$ input. It powers the discharge supply from an input voltage range of 95 to $140 \mathrm{~V}$ that covers the range of SOA spacecraft power busses and does not require development of high voltage parts. The discharge supply in this PPU is capable of supplying up to $800 \mathrm{~V}$ to a thruster with a specific impulse of $3,000 \mathrm{~s}$ and up to $14 \mathrm{~kW}$ of discharge power. The output current is limited to $20 \mathrm{~A}$. Also in this design, power for the magnet supplies comes from the $120 \mathrm{~V}$ input. Magnet power is only needed while discharge power is applied. This reduces the

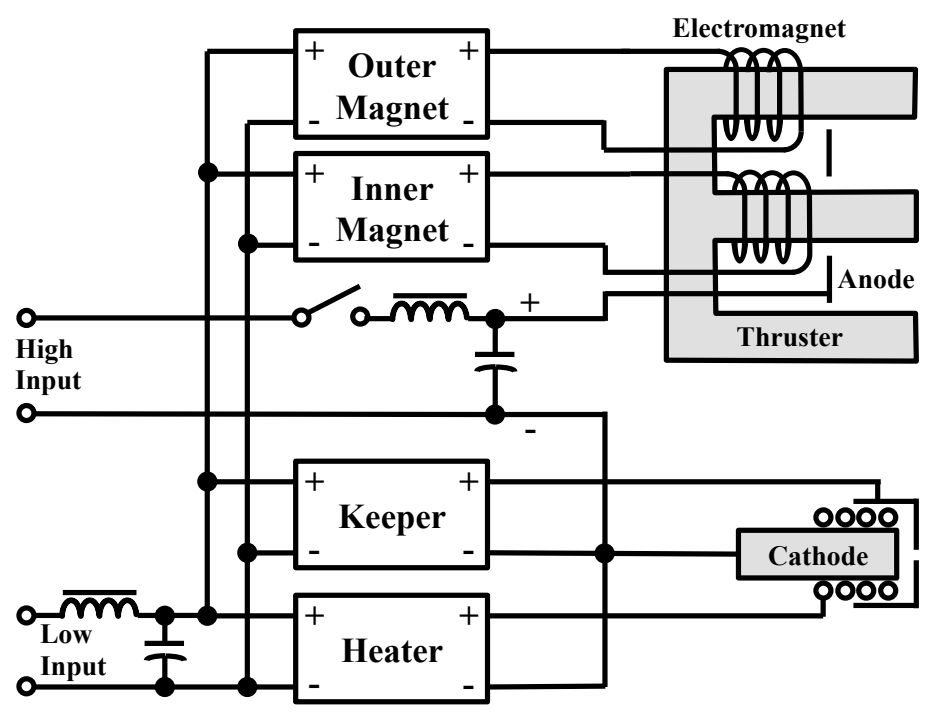

Figure 6. Simplified block diagram of a Hall DDU

circuit fault with a $1 \Omega$ resistor was applied across the discharge output. After "t0", the discharge voltage sags and the current spikes due to discharging of input power supply and discharge filter capacitors. After $20 \mathrm{~ms}$, the discharge voltage and current stabilize at approximately $80 \mathrm{~V}$ and $70 \mathrm{~A}$, respectively. After $45 \mathrm{~ms}$, at time " $\mathrm{t} 1$ ", the fault is cleared by the activation relay. The discharge voltage and current go to zero and the input voltage recovers.

JPL has conducted experiments with a $10 \mathrm{~kW}$ solar array to investigate technical problems associated with direct drive. ${ }^{17}$ Some of the biggest problems of direct-drive include the lack of electrical isolation in the discharge circuit which makes is difficult to operate multiple thrusters, determining how to handle ignitions, transients, and faults; understanding the effects of discharge current oscillations on the various spacecraft systems; developing techniques to force cathode current sharing when operating multiple thrusters; and

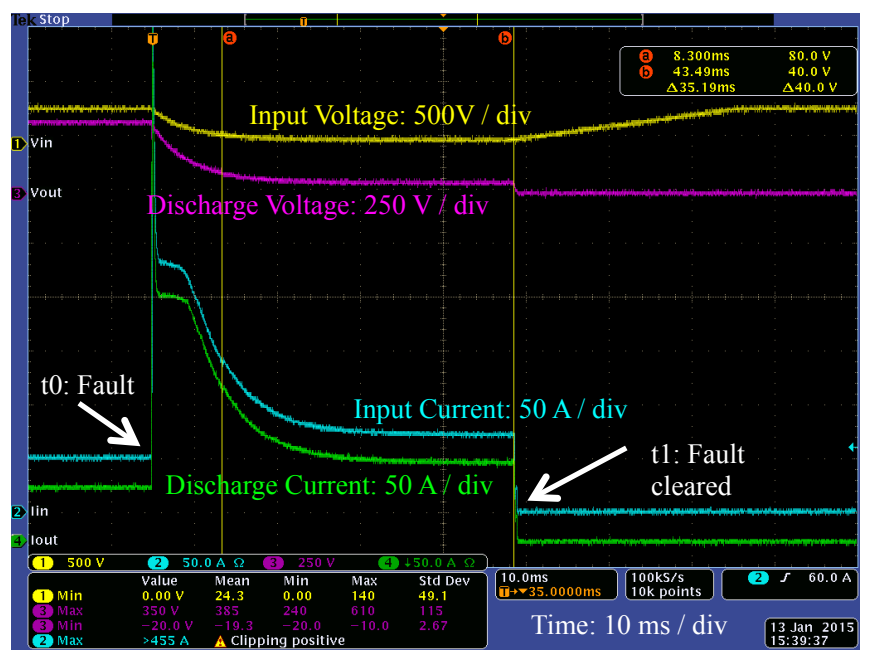

Figure 8. DDU voltage and current waveforms during simulated fault

6

American Institute of Aeronautics and Astronautics 
impact of the PPU on the $28 \mathrm{~V}$ power management and distribution system of the spacecraft. Keeper and heater power is still processed from the $28 \mathrm{~V}$ bus so that the thruster cathode can be operated during an eclipse. Table 2 summarizes the electrical input and output specifications used for this PPU.

Table 2. Electrical specifications for the $120 \mathrm{~V}$ PPU

\begin{tabular}{|c|c|c|c|c|}
\hline & Discharge & Magnets & Keeper & Heater \\
\hline $\begin{array}{l}\text { Output } \\
\text { Voltage }\end{array}$ & $300-800 \mathrm{~V}$ & $2-20 \mathrm{~V}$ & $10-30 \mathrm{~V}$ & $6-36 \mathrm{~V}$ \\
\hline $\begin{array}{l}\text { Output } \\
\text { Current }\end{array}$ & $10-20 \mathrm{~A}$ & $1-10 \mathrm{~A}$ & $1-3 A$ & $3-9 A$ \\
\hline $\begin{array}{c}\text { Maximum } \\
\text { Output } \\
\text { Power }\end{array}$ & $14 \mathrm{~kW}$ & $200 \mathrm{~W}$ & $90 \mathrm{~W}$ & $324 \mathrm{~W}$ \\
\hline $\begin{array}{l}\text { Regulation } \\
\text { Mode }\end{array}$ & $\begin{array}{c}\text { Voltage or } \\
\text { Current }\end{array}$ & & Current & \\
\hline $\begin{array}{l}\text { Line/Load } \\
\text { Regulation }\end{array}$ & \multicolumn{4}{|c|}{$\leq 2 \%$} \\
\hline Ripple & \multicolumn{4}{|c|}{$\leq 5 \%$} \\
\hline $\begin{array}{c}\text { Input } \\
\text { Voltage }\end{array}$ & \multicolumn{2}{|c|}{$95-140 \mathrm{~V}$} & \multicolumn{2}{|c|}{$23-36 \mathrm{~V}$} \\
\hline
\end{tabular}

\section{B. Design}

Reducing nominal input voltage by approximately $60 \%$ required a redesign of the discharge module to compensate for almost three times higher input currents. The target performance and the higher input current resulted in a discharge supply implementation with four discharge modules operating at a maximum of $3.5 \mathrm{~kW}$. Each discharge module was designed for an output voltage of up to $200 \mathrm{~V}$ and the outputs were stacked in series to generate the required $800 \mathrm{~V}$ output as shown in Fig. 9. However, when the required output voltage is lower than $400 \mathrm{~V}$, two of the four discharge modules can be disabled by command to increase loading and improve performance. Bypass diodes were included to further improve performance when operating in this mode. The full-bridge converter used for the discharge module has four MOSFETs in parallel on each leg of the bridge to reduce conduction losses. A commercially-available MOSFET with similar characteristics to a radiation-hardened, space-qualified MOSFET was used. Transformers and inductors were electrically and thermally designed to be similar to the $300 \mathrm{~V}$ PPU except for the geometry of the discharge power transformer core which used an E-core with a single winding on the center leg to reduce leakage inductance and improve coupling. Another part of the PPU that was significantly impacted by the lower input voltage is the $120 \mathrm{~V}$ input filter. The size of this filter increased so much that the master control board had to be a separate module.

The magnet power converters operating from the $120 \mathrm{~V}$ input were built using a half-bridge topology. This topology is simpler than the full-bridge topology used in the previous design with a $28 \mathrm{~V}$ input. Although, the halfbridge converter requires higher input currents, however, this is offset by operating at a higher input voltage. Figure 10 shows a photograph of the

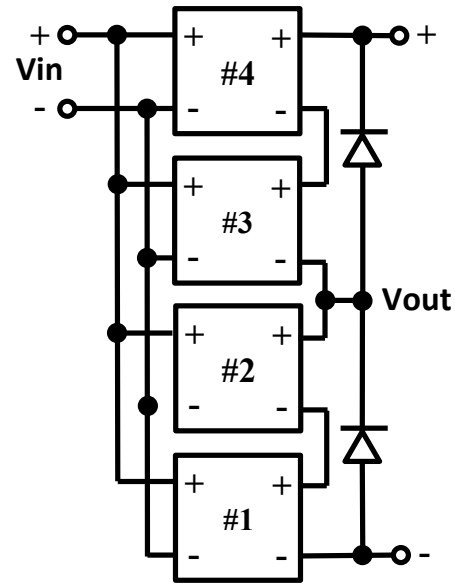

Figure 9. 120V PPU discharge supply configuration $120 \mathrm{~V}$ PPU. 


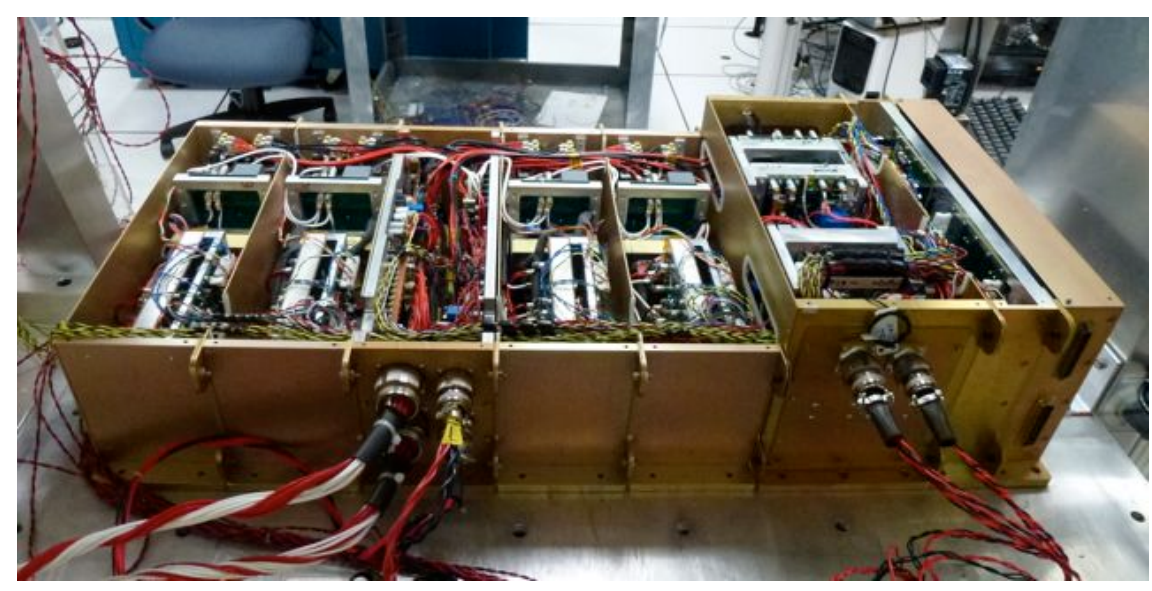

Figure 10. Photograph of 120V PPU

The mass of this brassboard PPU is $62 \mathrm{~kg}$. It is projected that after optimization of the converter design and packaging improvements, the mass could be reduced by at least 33 percent. This would result in a Hall PPU with a variable input voltage with a specific mass of less than $3 \mathrm{~kg} / \mathrm{kW}$ which compares favorably to SOA PPUs.

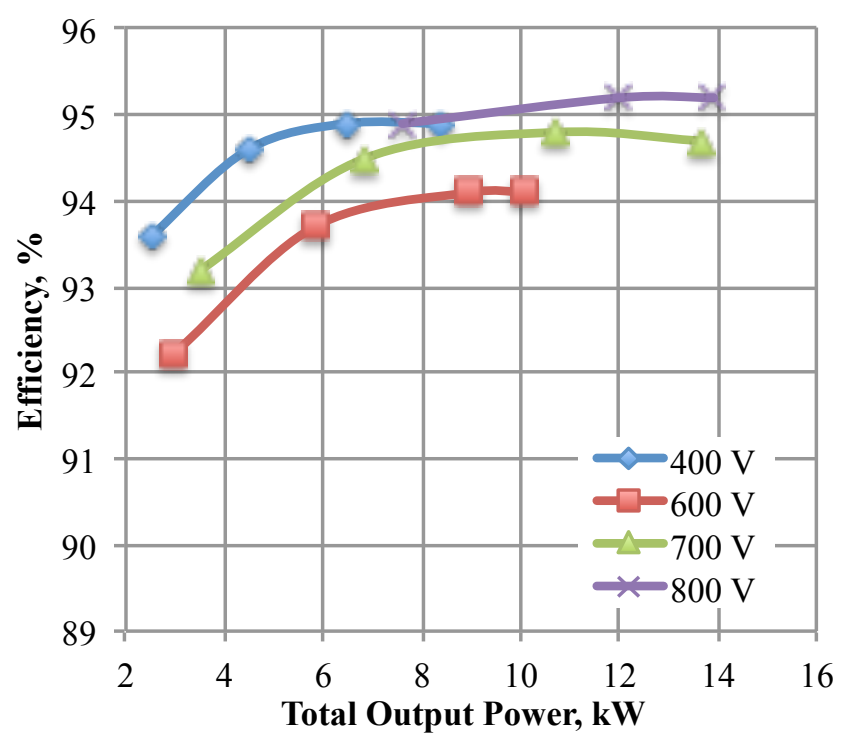

Figure 11. 120V PPU efficiency vs. total output power for several discharge voltages

\section{Testing}

The 120V PPU was bench top tested for performance and functionality. Figure 11 shows a plot of PPU total efficiency as a function of output power for several output voltages. With the magnet and keeper supplies operating at levels representative of the thruster, the PPU demonstrated total efficiencies in excess of $95 \%$ above $10 \mathrm{~kW}$ with a discharge voltage of $800 \mathrm{~V}$. The efficiency remains above $93 \%$ for most of the operating range. Other performance parameters and function operated within specifications.

Temperature measurements revealed a temperature rise of $50{ }^{\circ} \mathrm{C}$ for the discharge main power transformer and $30{ }^{\circ} \mathrm{C}$ for the discharge output inductor. The highest temperature rise was on the snubber resistors for the discharge output diodes at $55{ }^{\circ} \mathrm{C}$. The snubbers were required in this design to attenuate voltage spikes on the output diodes caused by the leakage inductance on the transformer and the junction capacitance of the

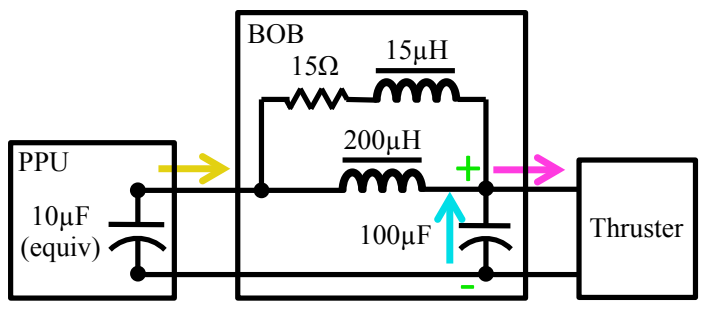

Figure 12. Final discharge filter configuration for thruster integration test

diodes. The temperature rise of other components was less than $20{ }^{\circ} \mathrm{C}$. Even though this PPU operates with slightly higher temperatures, all of them are still below derating guidelines for those components.

The discharge modules in the $120 \mathrm{~V}$ PPU were designed with an output filter that was sufficient to control the output voltage ripple while operating on a resistive load. However, thruster performance testing with laboratory power supplies indicated higher than expected discharge current oscillations on the HERMeS thruster. A larger filter capacitor was needed to control oscillations. Adding capacitance inside the PPU enclosure was impractical, so a $100 \mu \mathrm{F}$ capacitor was added external to the PPU. A $200 \mu \mathrm{H}$ inductor was also added externally to attenuate the PPU output current ripple. Figure 12 shows the final implementation of the filter used for thruster integration testing. 


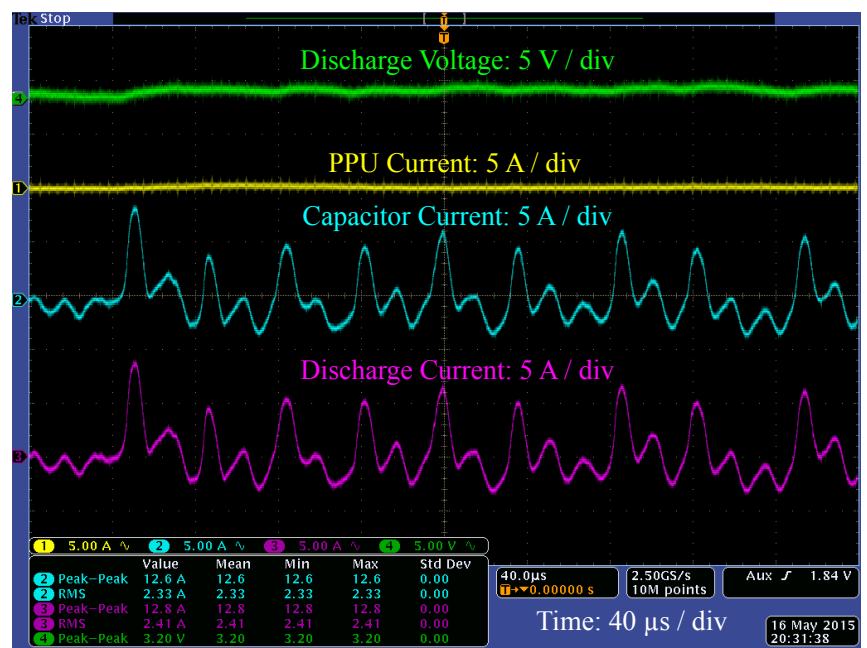

Figure 13. Waveforms of the discharge oscillations between the PPU and thruster
During the thruster integration test, the discharge supply output current, the additional filter capacitor current, and discharge current and voltage into the thruster were characterized. Figure 13 shows waveforms at an operating condition of $800 \mathrm{~V}$ and 15.7 A. As expected, the discharge current and the filter capacitor current are almost identical because most of the ripple current into the thruster is supplied by the filter capacitor. The filter inductor attenuates the discharge current ripple from the PPU. In this case, the peak-to-peak discharge current and voltage oscillations were approximately $12.8 \mathrm{~A}$ and $3.2 \mathrm{~V}$, respectively. This results in a voltage ripple of $\pm 0.2 \%$ which meets the requirement with substantial margin. This suggests that further reductions in capacitance are possible. However, additional testing and electrical modeling will be used to verify this.

VII. ABSS Discharge Module

Some SEP-TDM concepts considered the implementation of an unregulated $300 \mathrm{~V}$ solar array. Such an array could operate at a voltage as high as $580 \mathrm{~V}$, presenting a difficult challenge for the PPU. Without shunt regulation of the solar array, the PPU would have to be capable to start operating at this voltage before the array voltage transitions to the nominal operating point.

Whereas the $300 \mathrm{~V}$ SiC PPU demonstrated the benefit of using a high input voltage for a high power PPU and the potential of high-voltage $\mathrm{SiC}$ components, these parts are not qualified for space. In addition, high-voltage parts using the standard silicon technology are scarce and their performance is limited. Series-stacking the input of the power converters has also been proposed but this imposes a big risk to reliability because there is no guarantee that the voltage will be evenly distributed between modules. If an imbalance occurs during steady-state or transient operation, the converter could be compromised.

To circumvent the problem of a high voltage input, NASA GRC developed a converter known as the ABSS converter. A simplified schematic of this converter is shown in Fig. 14. The ABSS allows low voltage transistors to reliably process a high input voltage. The circuit uses four seriesstacked, full-bridge inverters connected to a common transformer. When the input voltage is at a maximum value of $600 \mathrm{~V}$, each inverter operates at $150 \mathrm{~V}$. The four identical primary windings are coupled by the same magnetic flux in the core forcing the input voltage to be evenly distributed between modules during steady-state and transient operating conditions.

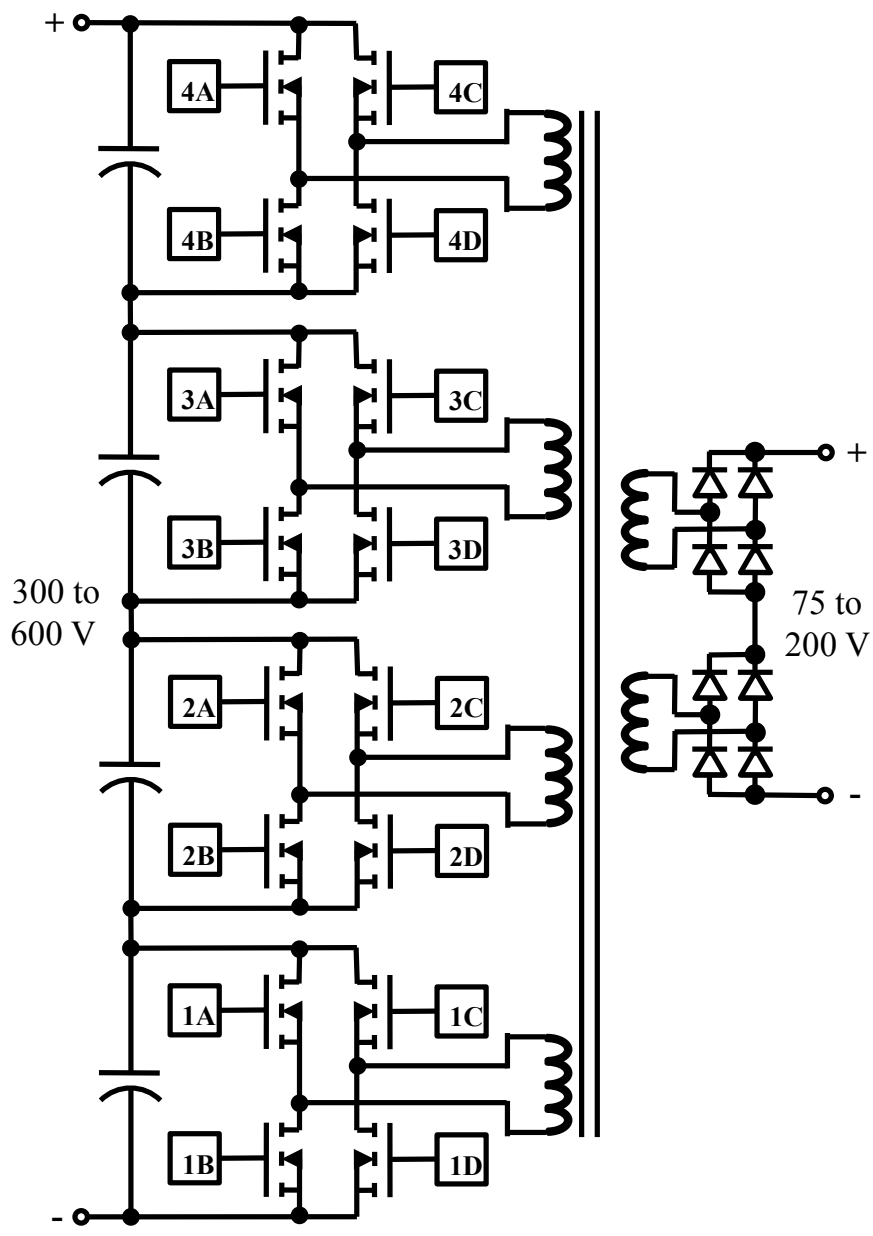

Figure 14. ABSS discharge converter simplified schematic 


\section{A Design}

Two brassboard discharge modules using the ABSS are being fabricated and tested as a risk reduction activity to demonstrate viability of this topology. Each module is capable of processing up to $4.0 \mathrm{~kW}$ of power from an input voltage of 300 to $600 \mathrm{~V}$ so each inverter within a module will operate between 75 and $150 \mathrm{~V}$. Two output rectifiers per module are connected in series to generate an output of up to $200 \mathrm{~V}$ and the outputs of the two modules will also be connected in a series to generate up to $400 \mathrm{~V}$. The four full-bridge inverters are driven by the same pulse-widthmodulation signals into isolated gate drives. Each inverter uses peak-current-mode control for fast line regulation and over-current protection. The transformer was designed using a similar approach as in the previous units. However, a U-core with a single winding was used in this case to keep the windings as simple and equal as possible so their performance would be closely matched.

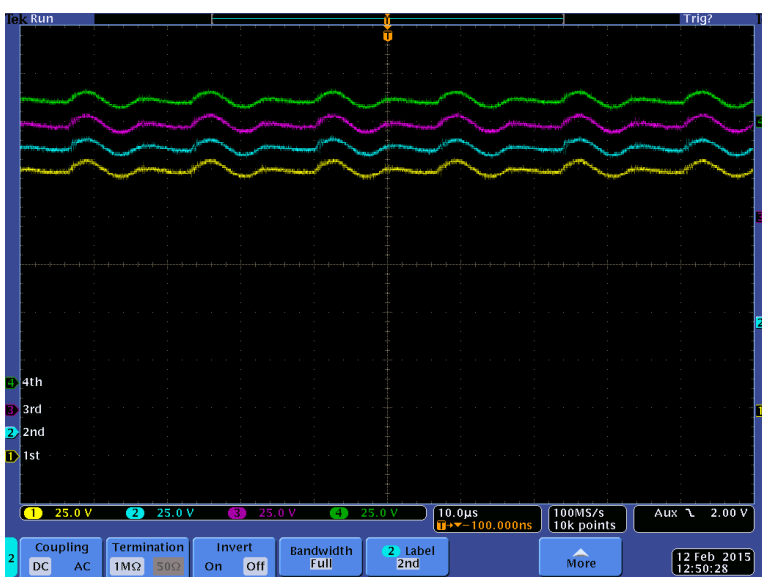

a)

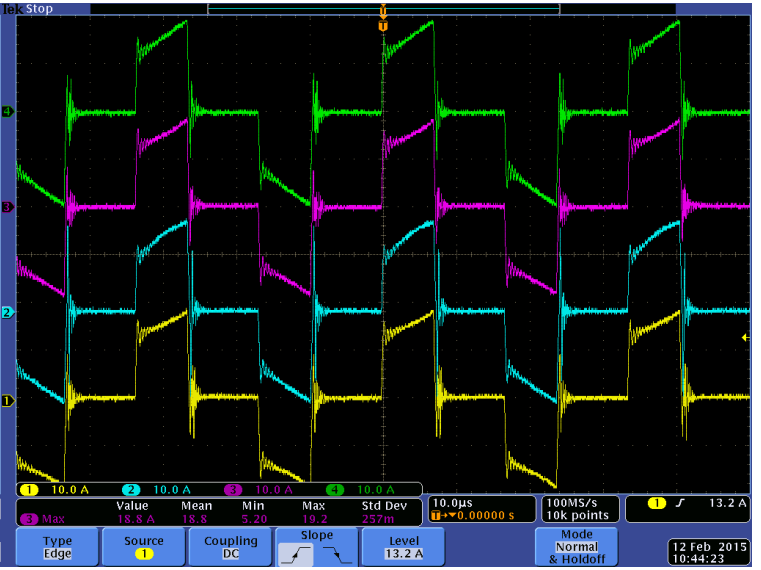

b)

Figure 15. ABSS converter steady-state waveforms: a) input capacitor voltage at $25 \mathrm{~V} / \mathrm{div}$ and b) transformer primary current at $10 \mathrm{~A} / \mathrm{div}$

\section{B. Testing}

Several tests were conducted to ensure the input voltage was evenly divided between the four series-stacked inverters at any operating condition. Figure 15(a) shows waveforms of the voltage at the input capacitor of each inverter and Fig. 15(b) shows the transformer primary current for each inverter. These waveforms show great balance and symmetry between all four inverters during steady-state operation at an input of $600 \mathrm{~V}$ and output of $200 \mathrm{~V}$. The same waveforms are shown for a 25\% step load reduction on Fig. 16(a) and 16(b). Also in this case of transient operation, the figures show that the voltage and current waveforms are symmetrical and well balanced.

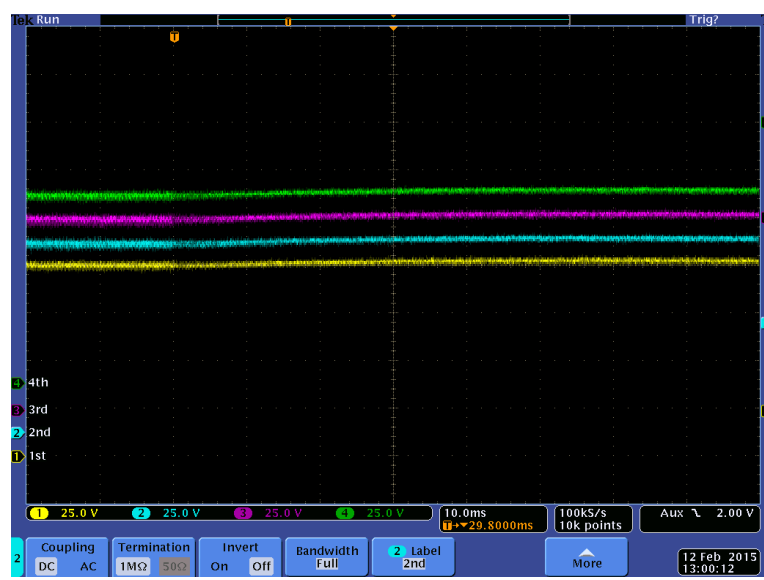

a)

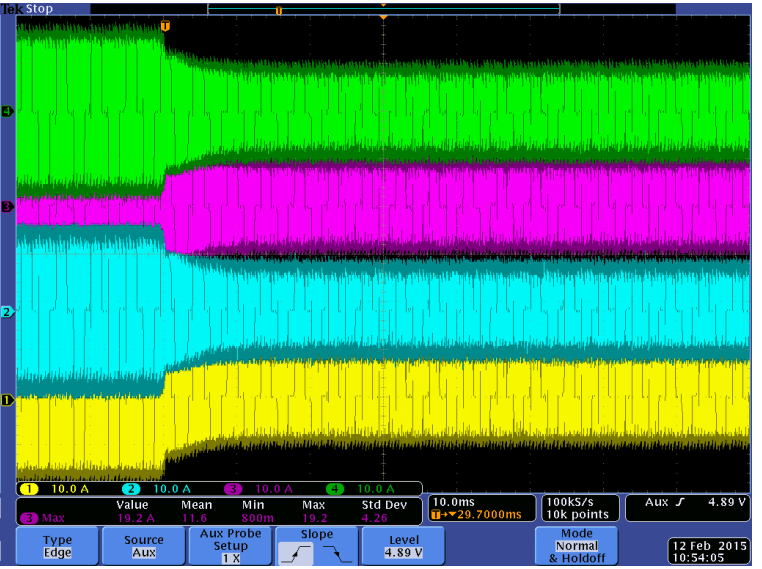

b)

Figure 16. ABSS converter transient waveforms: a) input capacitor voltage at $25 \mathrm{~V} / \mathrm{div}$ and b) transformer primary current at $10 \mathrm{~A} / \mathrm{div}$ 
Preliminary performance measurements of the ABSS converter were made. A maximum efficiency of $96.5 \%$ was measured at an input voltage of $300 \mathrm{~V}$ and full power condition of $4 \mathrm{~kW}$. At a maximum input voltage of $600 \mathrm{~V}$ and full power, efficiency was $95.5 \%$ which closely matches the efficiency of the $120 \mathrm{~V}$ PPU when operating at the high end of its input voltage range.

A preliminary reliability analysis was conducted on the ABSS converter. The analysis included only main power components like MOSFETs, diodes, transformers, inductors and capacitors. The reliability of the ABSS converter was found to be just $0.3 \%$ lower than a comparable full-bridge converter. A future activity to further validate this topology is a worst-case analysis to evaluate the effect of temperature, radiation and aging on the balanced operation of the inverters.

\section{Conclusion}

Several PPUs were designed, built and successfully tested at GRC in support of high power Hall system developments for STMD. A $300 \mathrm{~V} \mathrm{SiC} \mathrm{PPU} \mathrm{demonstrated} \mathrm{that} \mathrm{high} \mathrm{input} \mathrm{voltage} \mathrm{and} \mathrm{advanced} \mathrm{components} \mathrm{can}$ significantly improve PPU efficiency. However, radiation-hardened SiC components still have to be qualified for space flight applications. The ABSS discharge module demonstrated that a high input voltage PPU can be built using available radiation-hardened silicon MOSFETs at the cost of some added complexity. However, performance is still comparable to traditional designs. A $300 \mathrm{~V}$ DDU design demonstrated that direct-drive offers good improvements in mass and performance over SOA designs. However, high voltage solar arrays are needed and several system problems have to be solved before it is implemented on a spacecraft. Lastly, a 120V PPU demonstrated a viable design that could be used in the near future. At $95.5 \%$ efficiency, this PPU represents an improvement over SOA Hall thruster systems. The estimated mass of an optimized PPU packaged for flight is approximately $42 \mathrm{~kg}$ which compares favorably to SOA PPUs. With some additional development, any of these designs could become the basis of future flight PPU for planned NASA missions.

\section{Acknowledgements}

The authors would like to acknowledge the GRC PPU Team that supported the design, analysis, modeling, documentation, fabrication and testing of all the hardware developed for this project including: Danis Arthur, Michael Aulisio, Thomas Balogas, Michael Capelety, Edward Chisolm, Randy Clapper, Leon Collins, Justin Elckert, Henry Fain, Andrew Fausnaugh, James Fleet, Don Fong, Michael Garrett, Marcelo Gonzalez, Gary Gorecki, Elmer Griebeler, Ahmad Hammoud, David Hauser, Halbert Hoyett, Nedyalko Ivanov, Terrell Jansen, Hani Kamhawi, James King, Kevin McCormick, Michael McVetta, Beth Osborn, Michael Pastel, Thomas Ralys, Chip Redding, David Sicking, Louis Spinelli, Marcus Studmire, Paul Trimarchi, Long Truong, Tiffany Vanderwyst, Brandon White, Alex Yeckley, and Edward Zampino.

\section{References}

${ }^{1}$ Manzella, D., and Hack, K., "High-Power Solar Electric Propulsion for Future NASA Missions," AIAA-20143718, 50 ${ }^{\text {th }}$ AIAA/ASME/SAE/ASEE Joint Propulsion Conference, Cleveland, OH, July 28-30, 2014.

${ }^{2}$ Brophy, J. R. and Muirhead, B., "Near-Earth Asteroid Retrieval Mission (ARM) Study," IEPC-2013-082, $33^{\text {rd }}$ International Electric Propulsion Conference, George Washington University, USA, October 6-10, 2013.

${ }^{3}$ Smith, B., Nazario, M. L., and Manzella, D. H., "Advancement of a 30kW Solar Electric Propulsion System Capability for NASA Human and Robotic Exploration Missions," IAC-12-C4.4.2.

${ }^{4}$ Brophy, J.R., et al., "300-kW Solar Electric Propulsion System Configuration for Human Exploration of Near Earth Asteroids," AIAA Paper 2011-5514, $47^{\text {th }}$ AIAA/ASME/SAE/ASEE Joint Propulsion Conference, San Diego, CA, July 31 - August 3, 2011.

${ }^{5}$ McGuire, M. L., Hack, K. J., Manzella, D. H., and Herman, D. A., “ Concept designs for NASA's Solar Electric Propulsion Technology Demonstration Mission," AIAA-2014-3717, 50 ${ }^{\text {th }}$ AIAA/ASME/SAE/ASEE Joint Propulsion Conference, Cleveland, OH, July 28-30, 2014.

${ }^{6}$ Kamhawi, H., Huang, W., "Performance and Facility Background Pressure Characterization Tests of NASA's 12.5 kW Hall Effect Rocket with Magnetic Shielding Thruster," IEPC-2015-007, 34 ${ }^{\text {th }}$ International Electric Propulsion Conference, Hyogo-Kobe, Japan, July 4-10, 2015.

${ }^{7}$ Piñero, L.R., Peterson, P. Y., Bowers, G. E., "High Performance Power Module for Hall Effect Thrusters," AIAA 2002-3947, $38^{\text {th }}$ Joint Propulsion Conference, Indianapolis, Indiana, July 7-10, 2002.

${ }^{8}$ Piñero, L. R. et al., "Multi-Kilowatt Power Module for High-Power Hall Thrusters," $40^{\text {th }}$ AIAA Joint Propulsion Conference, AIAA-2004-3973, Fort Lauderdale, Florida, July 11-14, 2004. 
${ }^{9}$ Piñero, L.R., Hopson, M., Todd, P., and Wong, B., "Performance of the NEXT Engineering Model Power Processing Unit," AIAA-2007-5214, 43 ${ }^{\text {rd }}$ AIAA/ASME/SAE/ASEE Joint Propulsion Conference and Exhibit, Cincinnati, Ohio, July 8-12, 2007.

${ }^{10}$ Piñero, L.R., Bond, T., Okada, D., Pyter, J., Wiseman, S., "Design of a Modular 5-kW Power Processing Unit for the Next-Generation 40-cm Ion Engine," IEPC-01-329, $27^{\text {th }}$ International Electric Propulsion Conference, Pasadena, CA, October 14-19, 2002.

${ }^{11}$ Piñero, L. R. and Benson, S. W., "NEXT Engineering Model PPU Development, Progress and Plans," AIAA 2011-5659, 47 $7^{\text {th }}$ AIAA/ASME/SAE/ASEE Joint Propulsion Conference, San Diego, CA, July 31 - August 3, 2011

${ }^{12}$ Piñero, L. R., Kamhawi, H., and Drummond, G., "Integration Testing of a Modular Discharge Supply for NASA's High Voltage Hall Accelerator Thruster, "IEPC-2009-275, $31^{\text {st }}$ International Electric Propulsion Conference, Ann Arbor, MI, September 20 - 24, 2009.

${ }^{13}$ Hamley, J. A., Cardwell, G.I., McDowell, J., Bond, T., Matranga, M., "The Design and Performance Characteristics of the NSTAR PPU and DCIU," AIAA-98-3938, $34^{\text {th }}$ AIAA/ASME/SAE/ASEE Joint Propulsion Conference and Exhibit, Cleveland, Ohio, July 13- 15, 1998.

${ }^{14}$ Bond, T. A. and Christensen, J. A., "NSTAR Ion Thrusters and Power Processors," NASA/CR-1999-209162, November 1999.

${ }^{15}$ Piñero, L., Scheidegger, R., Aulisio, M., and Birchenough, A., "High Input Voltage Discharge Supply for High Power Hall Thrusters Using Silicon Carbide Devices," IEPC 2013-388, 33 ${ }^{\text {rd }}$ International Electric Propulsion Conference, George Washington University, USA, October 6-10, 2013.

${ }^{16}$ Bozak, K., et al., "High Input Voltage, Silicon Carbide (SiC) Power Processing Unit Performance Demonstration," Submitted for publication at AIAA Propulsion and Energy Forum 2015, Orlando, FL, July 27-29, 2015.

${ }^{17}$ Snyder, J. S., Brophy, J. R., Hofer, R. R., Goebel, D. M. and Katz, I., "Experimental Investigation of a DirectDrive Hall Thruster and Solar Array System at Power Levels up to $10 \mathrm{~kW}$," AIAA 2012-4068, 50 AIAA/ASME/SAE/ASEE Joint Propulsion Conference, Atlanta, GA, July 30 - August 1, 2012.

${ }^{18}$ Gollor, M., "Accommodation Aspects of Electric Propulsion with Power Processing Units and the Spacecraft", AIAA 2011-5651, $9^{\text {th }}$ Annual International Energy Conversion Engineering Conference, San Diego, CA, July 31 August 3, 2011.

${ }^{19}$ Schneider, T.,Hovater, M., Carruth, M. R., Mikellides, I. G., Jongeward, G. A., Peterson, T., Kerslake, T. W., Snyder, D., Ferguson, D., and Hoskins, A., "Plasma Interactions with High Voltage Solar Arrays for a Direct Drive Hall Effect Thruster System," AIAA Paper 2003-5017, $39^{\text {th }}$ Joint Propulsion Conference, Huntsville, AL, July 2023, 2003. 